\title{
Peripheral T cell lymphoma, not otherwise specified: the stuff of genes, dreams and therapies
}

\author{
C Agostinelli, ${ }^{1}$ P P Piccaluga, ${ }^{1}$ P Went, ${ }^{2}$ M Rossi, ${ }^{1}$ A Gazzola, ${ }^{1}$ S Righi, ${ }^{1}$ T Sista, ${ }^{1}$ \\ C Campidelli, ${ }^{1}$ P L Zinzani, ${ }^{1}$ B Falini, ${ }^{3}$ S A Pileri ${ }^{1}$
}

${ }^{1}$ Department of Haematology and Clinical Oncology "L and A Seràgnoli", Bologna University School of Medicine, Bologna, Italy; ${ }^{2}$ Institute of Pathology, Triemli Hospital, Zurich, Switzerland: ${ }^{3}$ Institute of Haematology, Perugia University School of Medicine, Perugia, Italy

Correspondence to:

Professor Stefano A Pileri, Chair of Pathology and Unit of Haematopathology, Department of Haematology and Clinical Oncology "L and A Seràgnoli",

St Orsola Hospital, Via

Massarenti 9, 40138 Bologna,

Italy; stefano.pileri@unibo.it

CA and PPP contributed equally to this work.

Accepted 29 July 2008

Published Online First

28 August 2008

\section{ABSTRACT}

Peripheral T cell lymphomas (PTCL) account for about $12 \%$ of lymphoid tumours worldwide. Almost half show such morphological and molecular variability as to hamper any further classification, and to justify their inclusion in a waste-basket category termed "not otherwise specified (NOS)". The latter term is used for neoplasms with aggressive presentation, poor response to therapy and dismal prognosis. In contrast to B cell lymphomas, PTCL have been the subject of only a limited number of studies to elucidate their pathobiology and identify novel pharmacological approaches. Herewith, the authors revise the most recent contributions on the subject based on the experience they have gained in the extensive application of microarray technologies. PTCL/NOS are characterised by erratic expression of $\mathrm{T}$ cell associated antigens, including CD4 and CD52, which have recently been proposed as targets for ad hoc immunotherapies. PTCL/ NOS also show variable Ki-67 marking, with rates $>80 \%$ heralding a worse prognosis. Gene expression profiling studies have revealed that PTCL/NOS derive from activated $T$ lymphocytes, more often of the CD4+ type, and bear a signature composed of 155 genes and related products that play a pivotal role in cell signalling transduction, proliferation, apoptosis and matrix remodelling. This observation seems to pave the way for the use of innovative drugs such as tyrosine kinase and histone deacetylase inhibitors whose efficacy has been proven in PTCL primary cell cultures. Gene expression profiling also allows better distinction of PTCL/NOS from angioimmunoblastic $T$ cell lymphoma, the latter being characterised by follicular $\mathrm{T}$ helper lymphocyte derivation and CXCL13, PD1 and vascular endothelial growth factor expression.

Peripheral T cell lymphomas (PTCL) represent approximately $12 \%$ of lymphoid neoplasms. ${ }^{1}$ Their incidence varies among countries, and it is higher in human T-cell lymphotropic virus-1 endemic areas. ${ }^{1}$ PTCL are a heterogeneous group of tumours that can be roughly subdivided into: specified and not otherwise specified (NOS) (Box 1). ${ }^{12}$ While specified tumours correspond to distinct but rare entities often occurring at extranodal sites, NOS represent the commonest type of TCL (40-50\%), followed by the angioimmunoblastic (AITL) and the anaplastic large cell (ALCL) types.

PTCL/NOS cannot be further classified based on morphology, phenotype and molecular biology in most instances, ${ }^{3-5}$ although rare distinctive variants have been reported (ie, follicular and lymphoepithelioid). ${ }^{6-8}$ Usually, PTCL/NOS occurs in the fifth to sixth decade of life, and there is no evidence of sex predilection. ${ }^{4910}$ PTCL/NOS more often presents in stage III-IV, with nodal, skin, liver, spleen, bone-marrow or peripheral blood involvement. ${ }^{4} 910$

The tumour is highly variable in terms of cell morphology and may contain prominent reactive components. $^{13}$

Immunohistochemistry usually shows $\mathrm{T}$ cell associated molecule expression, although the phenotypic profile is aberrant in about $80 \%$ of cases. ${ }^{13}$

Clonal rearrangements of $\mathrm{T}$ cell receptor encoding genes are generally detected. ${ }^{11}$ The karyotype is aberrant in most cases, and is often characterised by complex abnormalities. ${ }^{12}$ Recently, recurrent chromosomal gains and losses have been documented in PTCL/NOS by comparative genomic hybridisation, and these have been found to differ from those seen in AITL and ALCL. ${ }^{12}{ }^{13}$

The molecular pathobiology of PTCL/NOS, as in general in all $\mathrm{T}$ cell neoplasms, is poorly understood. In particular, only limited numbers of studies have explored the gene expression profile (GEP). ${ }^{14-22}$

On clinical grounds, PTCL/NOS are among the most aggressive non-Hodgkin lymphomas. Their response to conventional chemotherapy is indeed poor, with 5-year relapse-free and overall survival rates of $26 \%$ and $20 \%$, respectively. ${ }^{4}{ }^{9}{ }^{23-26}$ Neither the morphology nor the international prognostic index (IPI) significantly correlates with the outcome. Clinical or clinicobiological scores have been proposed to identify cases with different prognoses. ${ }^{26}{ }^{27}$ However, the molecular bases of PTCL/ NOS drug resistance and aggressiveness remain elusive.

In the following, the results recently obtained by our group through the extensive application of microarray technologies will be summarised and commented on, with the scope of defining the pathobiological characteristics of PTCL/NOS, tracing the borders between it and AITL on the one hand and anaplastic large cell lymphoma kinase (ALK)-negative ALCL on the other, and drawing attention to potentially novel prognosticators and therapeutic targets. ${ }^{19-22} 27$

\section{PHENOTYPIC PROFILE OF PTCL/NOS}

As mentioned above, PTCL/NOS usually carry phenotypic aberrations, the exact prevalence and spectrum of which have remained unresolved. 8112528 In 2006, we reported PTCL from 193 Italian patients (148 NOS and 45 AITL) that had been collected on tissue microarrays and tested by immunohistochemistry and Epstein-Barr virus encoded RNA 1 (EBER1) and EBER2 in situ
This paper is freely availat online under the BMJ Journa unlocked scheme, see http./ jcp.bmj.com/info/unlocked.dt| 


\section{Box 1: Mature T cell and NK cell neoplasms'}

Peripheral T cell lymphoma, not otherwise specified (PTCL/ NOS)

Peripheral T cell lymphoma, specified

Leukaemic:

- T cell prolymphocytic leukaemia

- T cell large granular lymphocytic leukaemia

- Aggressive NK cell leukaemia

- Systemic Epstein-Barr virus positive T cell lymphoproliferative disease of childhood (associated with chronic active EBV infection)

- Hydroa vaccineforme-like lymphoma

- Adult T cell leukaemia/lymphoma

Extranodal:

- Extranodal NK/T cell lymphoma, nasal type

- Enteropathy-associated T cell lymphoma

- Hepatosplenic T cell lymphoma

- Subcutaneous panniculitis-like T cell lymphoma

- Mycosis fungoides

- Sézary syndrome

- Primary cutaneous anaplastic large-cell lymphoma

- Primary cutaneous aggressive epidermotropic CD8+ cytotoxic T cell lymphoma (provisional entity)

- Primary cutaneous $\gamma \delta$ T cell lymphoma

- Primary cutaneous small/medium CD4+ T cell lymphoma (provisional entity)

Prevalently nodal:

- Angioimmunoblastic T cell lymphoma

- Anaplastic large cell lymphoma (ALCL), anaplastic large cell lymphoma kinase (ALK) positive

- ALCL, ALK negative (provisional entity)

hybridisation. ${ }^{27}$ The $\beta F 1$ antibody (raised against the $\mathrm{T}$ cell receptor $\beta$ chain) reacted with $96 \%$ of tumours. NOS and AITL PTCL demonstrated frequent loss of CD5 and CD7, with CD3 being the conventional marker most commonly expressed in NOS types, and CD2 in the AITL types. CD4 was detected in $46 \%$ of cases (see fig $1 \mathrm{~A}$ ) and CD8 in 15\% of cases; these results are in line with those reported in previous publications. ${ }^{8} 11252829$ Interestingly, we found $32 \%$ of AITLs to be CD8+; this is in the upper range of reported values. ${ }^{27}{ }^{30-44}$ In contrast, the incidence of CD4 positivity (42\%) was much lower than expected. ${ }^{27} 45$ Interestingly, a huge number of PTCL/NOS and AITL (55\%) turned out to be either CD4/CD8 double-negative or, more rarely, double-positive. Such profiles, which are usually observed during intrathymic $\mathrm{T}$ cell development, ${ }^{127}$ had previously been reported in isolated PTCL cases $^{46}{ }^{47}$ and a proportion of cutaneous $\mathrm{T}$ cell tumours. ${ }^{27}{ }^{48}$ Furthermore, CD10 expression was detected in only 39\% of AITL, even when adopting a low cut-off value. ${ }^{27}$ Such rates did not vary between tissue microarrays and conventional sections.

CD56 was detected in 5\% of PTCL/NOS: all cases stained with $\beta \mathrm{F} 1$ and three co-expressed TIA-1. Interestingly, CD56 expression suggests a malignant phenotype: in fact, under physiological conditions it is limited to $\mathrm{T}$ lymphocytes with spontaneous non-MHC-restricted cytotoxicity. ${ }^{27}{ }^{49}$ CD57 was seen in $10 \%$ and $5 \%$ of PTCL/NOS and AITL respectively. Although numbers of CD57+ normal $\mathrm{T}$ lymphocytes increase with age, ${ }^{49}$ no correlation was found between patient age and CD57 expression. ${ }^{27} 50$
CD30 was recorded in 6\% of cases (see fig 1B), CD15 in 4\%, and $\mathrm{CD} 20$ in $1 \%^{27}$; these rates of positivity may undoubtedly cause diagnostic difficulties. In particular, CD20 was detected in only two PTCL/NOS that were negative for CD79a, in keeping with previous observations of CD20 positivity in isolated PTCL/ NOS, and CD79a aberrant expression in "specified" PTCL. ${ }^{27}$ 51-53 Co-expression of CD15 and CD30 was found in only 3/183 of cases that were able to be evaluated. This is the first reliable estimate of the random incidence of such a phenomenon in a large cohort of patients with PTCL; in fact, the previous reports of Barry et $a l^{54}$ and Gorczyka et a $\left.\right|^{55}$ referred to a highly selected series. In spite of its rarity, such a finding raises the question of how to differentiate between PTCL and classic Hodgkin lymphoma (CHL) under these circumstances: the polymorphism of neoplastic elements, the possible lack of Reed-Sternberg cells and B cell specific activator protein negativity favour the diagnosis of PTCL and vice versa. In particular, B cell specific activator protein is a valuable $\mathrm{B}$ cell marker that is found in about $90 \%$ of cases of $\mathrm{CHL},{ }^{56}$ but it is exceptional in PTCL/ NOS. ${ }^{57}$

In our hands, the mean percentage of $\mathrm{Ki}-67+$ neoplastic cells was around $50 \%$, with $11 \%$ of PTCL/NOS exceeding the $80 \%$ value. Finally, EBV integration was found at the neoplastic cell level in $5 \%$ and $3 \%$ of PTCL/NOS and AITL respectively; this value is definitely lower than the one recorded by Dupuis et al in a French cohort. ${ }^{58}$

\section{GEP OF PTCL/NOS}

PTCL have been the subject of a limited number of GEP studies $^{14-225960}$ (table 1). In particular, Tracey et al ${ }^{60}$ Lamant et $a l^{16}$ and de Leval et $a l^{17}$ focused on mycosis fungoides, ALKpositive and -negative ALCLs, and AITL, respectively. In contrast, Martinez-Delgado et a $l^{14}$ and Ballester et a ${ }^{15}$ analysed large collections of PTCL of the NOS, AITL and ALCL types. However, their studies suffered limitations that varied from the usage of chips with a restricted number of genes ${ }^{14}{ }^{15}$ to the lack of a reliable normal counterpart for comparison. ${ }^{14}$ MartinezDelgado $e t a l^{14}$ reported that PTCL/NOS corresponded to a heterogeneous group of tumours whose GEP was difficult to interpret due to the amount of infiltrating reactive cells. According to those authors, the only clinically relevant information provided by GEP pertains the NF- $\mathrm{kB}$ gene expression level (see below). ${ }^{14}$ Ballester et $a l^{15}$ reported that GEP could discriminate among PTCL of the NOS, AITL and ALCL types, although NOS did not share a single profile. Using a multiclass predictor, the authors separated their cases into three molecular subgroups: U1, U2 and U3. However, the corresponding signatures might have been, at least in part, influenced by reactive components, as suggested by the fact that, for instance, the U3 subgroup consisted almost entirely of histiocyte-rich tumours.

Recently, we ${ }^{20}$ published a GEP study based on the analysis of $28 \mathrm{PTCL} / \mathrm{NOS}$, all corresponding to lymph node biopsy samples containing an amount of neoplastic cells exceeding $70 \%$ value of the whole examined population. The mRNA extracted from these cases was hybridised on the HG U133 2.0 Plus gene chip. The results obtained were compared with those of six AITL, six ALCL (two ALK-positive and four ALK-negative) and 20 samples of normal $\mathrm{T}$ lymphocytes, which were purified from the peripheral blood and tonsil and corresponded to the main $\mathrm{T}$ cell subsets (CD4+, CD8+, resting and activated). Such a study significantly differed from most previous reports ${ }^{14} 60$ in terms of methodology and selection criteria. In addition, for the first time it provided the rationale for possible targeted therapies 
Figure 1 (A) Lymphomatous cells do not express CD4; however, CD4 is detected in some reactive small lymphocytes (alkaline phosphatase antialkaline phosphatase (APAAP) technique, Gill's haematoxylin nuclear

counterstaining, $\times 250$ ). (B) Partial CD30 expression; it should be noted that the tumour has no anaplastic morphology (APAAP technique, Gill's haematoxylin nuclear counterstaining, $\times 250$ ). (C) Positivity for platelet-derived growth factor receptor $\alpha$ (PDGFR $\alpha$ ) (APAAP technique, Gill's haematoxylin nuclear counterstaining, $\times 400$ ). (D) PDGFR $\alpha$ is phosphorylated (APAAP technique, Gill's haematoxylin nuclear counterstaining, $\times 400$ ). (E) CXCL13 expression by neoplastic elements in angioimmunoblastic T cell (EnVision+ technique, Gill's haematoxylin nuclear counterstaining, $\times 100)$. (F) Ki-67 marking exceeds the $80 \%$ value (EnVision+ technique, Gill's haematoxylin nuclear counterstaining, $\times 200$ ). (G) CD52 positivity in a peripheral T cell lymphoma, not otherwise specified (APAAP technique, Gill's haematoxylin nuclear counterstaining, $\times 100)$. (H) Strong expression of vascular endothelial growth factor in an angioimmunoblastic T cell lymphoma (EnVision+ technique, Gill's haematoxylin nuclear counterstaining, $\times 200$ ).
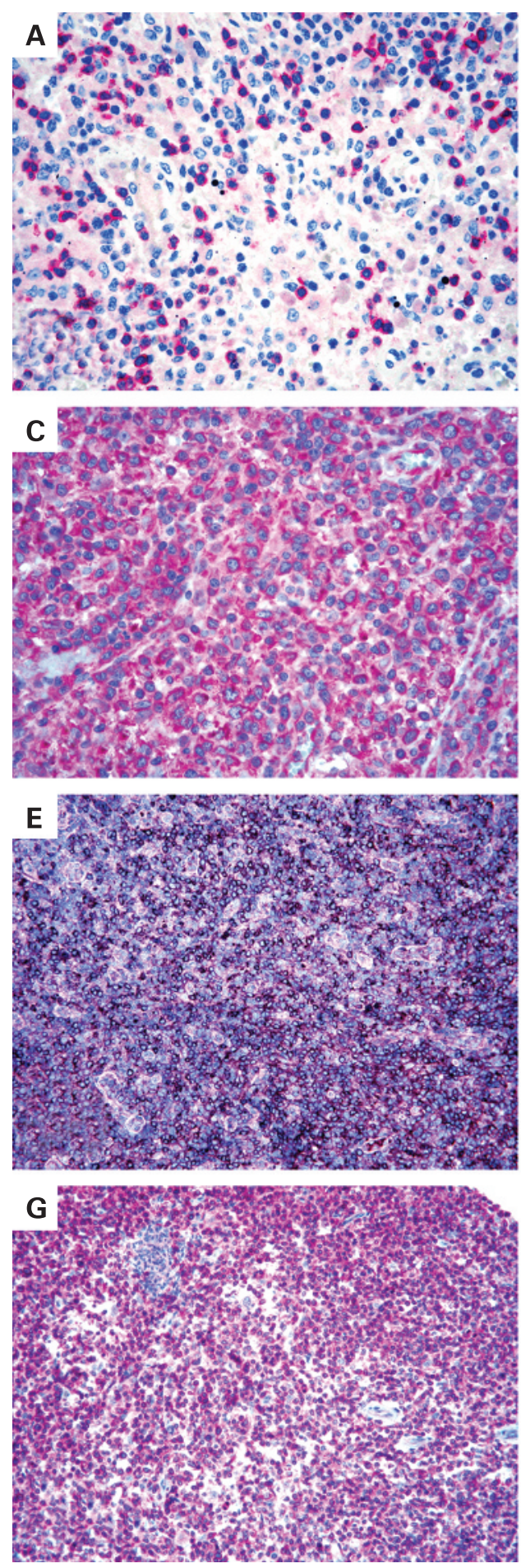
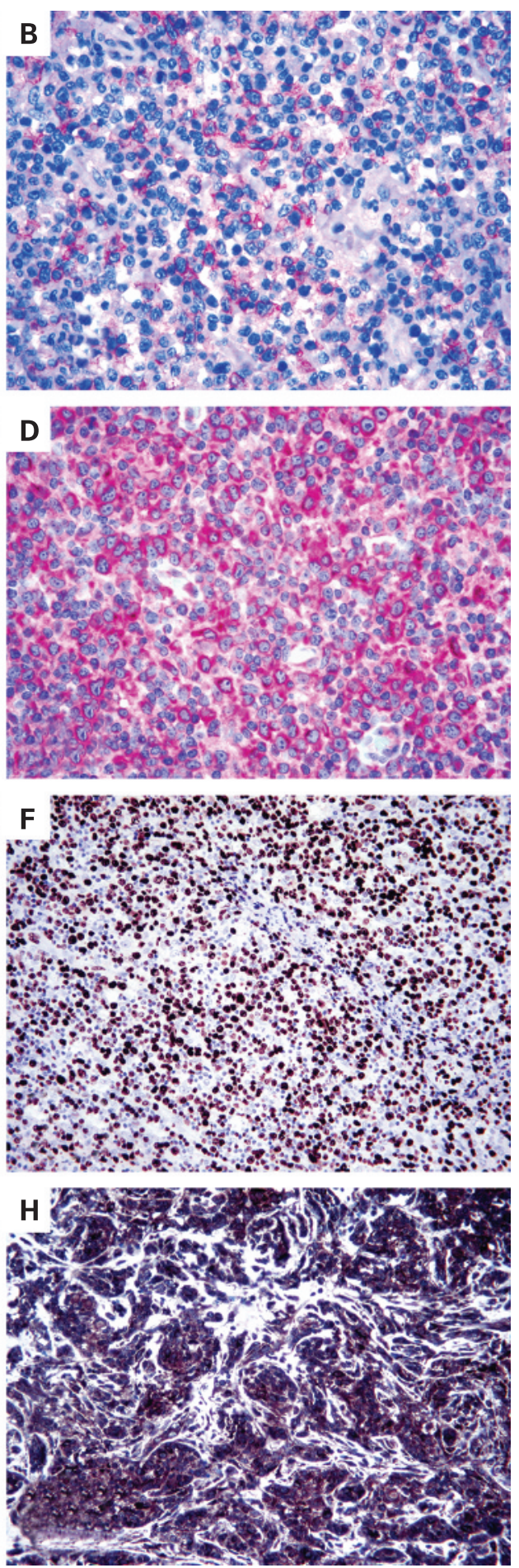

in PTCL/NOS by offering clear evidence of their ex vivo effectiveness.

In particular, the GEP we detected ${ }^{20}$ indicated that PTCL/ NOS are distinct from normal $\mathrm{T}$ and $\mathrm{B}$ lymphocytes and are more closely related to activated rather than resting $T$ cells. As in normal mature $\mathrm{T}$ lymphocytes, it was possible to identify two main subgroups of PTCL/NOS, with GEPs related to either CD4 or CD8 elements. Notably, this characteristic did not reflect the expression of CD4 and CD8 molecules.

In addition to histogenetic information, our analysis ${ }^{20}$ provided several insights into the functional alterations of
PTCL/NOS. A careful comparison of PTCL/NOS with the closest normal counterparts revealed the systematic deregulation of 155 genes controlling functions that are typically damaged in malignant cells, such as matrix remodelling, cell adhesion, transcription, proliferation and apoptosis. In particular, our findings might explain the dissemination pattern of PTCL/NOS, with frequent extranodal and bone-marrow involvement and spread to peripheral blood, ${ }^{1}$ by showing the upregulation of FN1, LAMB1, COL1A2, COL3A1, COL4A1, COL4A2, and COL12A1 (ie, genes that promote local invasion and metastasis in different types of human cancer). ${ }^{61-63}$ In 
Table 1 The main studies dealing with gene expression profiling of peripheral T cell lymphomas

\begin{tabular}{ll}
\hline Reference & Disease(s) \\
\hline Tracey et al $^{60}$ & FM \\
Martinez-Delgado et al ${ }^{14}$ & PTCL/NOS \\
Martinez-Delgado et al ${ }^{98}$ & PTCL/NOS
\end{tabular}

Comments

Ballester et al ${ }^{15} \quad$ PTCL/NOS, AlLT, ALCL

The GEP of FM was investigated, and it showed concurrent deregulation of multiple genes involved in the tumour
necrosis factor signalling pathway.

The authors found significant differences between the peripheral and lymphoblastic $T$ cell lymphomas. The differences included a deregulation of the nuclear factor- $\mathrm{KB}$ signalling pathway.

Martinez-Delgado et al sen-PTCL/NOS The authors found two different subgroups of PTCL based on the expression of NF- $\mathrm{KB}$ related genes. One-third of PTCL clearly showed reduced expression of NF-KB genes, while the other group was characterised by high expression of these genes. Of interest, the expression profile associated with reduced expression of NF- $\mathrm{kB}$ genes was significantly associated with shorter survival of patients.

According to this study, PTCL/NOS could be divided into three molecular subgroups: U1, U2 and U3. The U1 gene expression signature included genes known to be associated with poor outcome in other tumours, such as CCND2. The U2 subgroup was associated with overexpression of genes involved in T cell activation and apoptosis, including NF-KB1 and BCL-2. The U3 subgroup was mainly defined by overexpression of genes involved in the IFN/ JAK/STAT pathway. Notably, such distinction possibly reflected, at least in part, the presence of reactive components in the PTCL samples.

de Leval et al ${ }^{17} \quad$ All

The molecular profile of AILT was characterised by a strong microenvironment and overexpression of several genes characteristic of normal follicular helper T (TFH) cells: CXCL13, BCL6, PDCD1, CD40L and NFATC1. Such a finding was reinforced by gene set enrichment analysis, which demonstrated that the AITL molecular signature was significantly enriched in TFH-specific genes.

Piccaluga et al ${ }^{20} \quad$ PTCL/NOS

The authors showed that PTCL/NOS are most closely related to activated peripheral T lymphocytes, either CD4+ or CD8+, based on the GEP. In addition, PTCL/NOS displayed deregulation of relevant functional cell programmes. In particular, among others, PDGFRA, a gene encoding for a tyrosine kinase receptor, turned out to be aberrantly expressed by PTCL/NOS. Notably, phosphorylation of PDGFRA and sensitivity of cultured PTCL cells to imatinib were demonstrated.

Piccaluga et al ${ }^{21} \quad$ PTCL/NOS The authors found that CD52 is expressed in approximately $40 \%$ of PTCL/NOS at the same level as in normal T lymphocytes, being aberrantly downregulated in the remaining cases. Notably, they concluded that the estimation of CD52 expression may provide a rationale for the selection of patients with a higher probability of response to the anti-CD52 antibody alemtuzumab.

Piccaluga et al ${ }^{22} \quad$ AlLT

In this manuscript, the authors reported that AlLT and other PTCL have rather similar GEP, possibly sharing common oncogenic pathways. In addition, they found that the molecular signature of follicular T helper cells was significantly overexpressed in AlLT. Finally, several genes, such as PDGFRA and VEGF, which are deregulated in AlLT and represent potential therapeutic targets, were identified.

Lamant et al ${ }^{16} \quad$ ALCL

This was the first study to focus on ALCL. Unsupervised analysis classified ALCL in two clusters, corresponding essentially to morphological subgroups and clinical variables. Supervised analysis showed that ALK-positive ALCL and ALK-negative ALCL have different GEP, further confirming that they are different entities.

Cuadros et al ${ }^{18} \quad$ PTCL/NOS

Five clusters of genes were identified, and their expression varied significantly among the samples. Genes in these clusters were functionally related to different cellular processes such as proliferation, inflammatory response, and T cell or B cell lineages. Notably, overexpression of genes in the proliferation signature was significantly associated with shorter survival of patients.

AlLT, peripheral T cell lymphoma, angioimmunoblastic type; ALCL, anaplastic large cell lymphoma; ALK, anaplastic large cell lymphoma kinase; FM, mycosis fungoides; GEP, gene expression profile; PDGFRA, platelet-derived growth factor receptor $\alpha$; PTCL/NOS, peripheral T cell lymphoma, not otherwise specified.

addition, it revealed the deregulation of genes involved in apoptosis (eg, MOAP1, ING3, GADD45A and GADD45B) (4470 $^{-1}$ and chemoresistance (such as CYR61 and NNMT). ${ }^{61-63}$ 71-82

Immunohistochemistry provided in situ validation of the genomic data by showing correspondence between mRNA and protein expression, as seen, for example, with GEP, PDGFR $\alpha$ (see fig $1 \mathrm{C}$ and D) and BCL10. In addition, by comparison with normal tissues, immunohistochemistry allowed the identification of staining patterns corresponding to the synthesis of ectopic or paraphysiological products by neoplastic cells. Finally, the phenotypic test highlighted the possibility that some of the results obtained by GEP may depend on non-neoplastic components present in the analysed sample, as seen for Caldesmon.

In the course of the same study, we found that all ALCLs tended to cluster together - irrespective of their ALK positivity or negativity - showing a signature distinct from those of PTCL/NOS and AITL. ${ }^{20}$

More recently, we succeeded in identifying a gene signature discriminating between PTCL/NOS and AITL (fig 2). ${ }^{22}$ In addition, the observed AITL global profile strengthened its derivation from the follicular $\mathrm{T}$ helper lymphocyte $\left(\mathrm{FT}_{\mathrm{H}} \mathrm{L}\right)$, as originally proposed by Rüdiger et a ${ }^{133}$ and de Leval et al. ${ }^{17}$ Among upregulated genes, were those encoding for CXC13, PD1 and vascular endothelial growth factor (VEGF).

\section{PRACTICAL IMPLICATIONS OF PHENOTYPIC AND MOLECULAR FINDINGS \\ Diagnosis}

Along with clonality studies, ${ }^{11}$ the phenotype plays a basic role in the distinction of PTCL from reactive conditions-such as paracortex hyperplasia - that can mimic malignant lymphoma. In fact, the lack of one or more $\mathrm{T}$ cell associated antigens (see above) is a hallmark of neoplastic cells as opposed to the complete phenotype of normal $\mathrm{T}$ lymphocytes. ${ }^{27}$ Immunohistochemical and molecular findings are also of great value for differential diagnosis among PTCL.

\section{PTCL/NOS versus AITL}

Such distinction may be problematic in about $25 \%$ of cases, based on conventional criteria. ${ }^{84}$ Also CD10 staining, proposed as characteristic of AITL, ${ }^{85} 86$ is actually seen in less than $50 \%$ of cases in our experience. ${ }^{27}$

Notably, the AITL gene signature recently reported by de Leval $e \mathrm{al}^{17}$ and our group ${ }^{22}$ (see above) provides a rationale to the immunohistochemical observations of Dupuis et al ${ }^{87}$ Grogg et $a l^{88}$ and Roncador et $a l^{89}$ who found that most, if not all, AITL stain for typical $\mathrm{FT}_{\mathrm{H}} \mathrm{L}$-related antigens, such as CXCL13 (see fig 1E) and PD-1. Such molecules can actually represent a powerful tool for the distinction of AITL from PTCL/NOS, due to the exceptional positivity of the latter, a finding also 


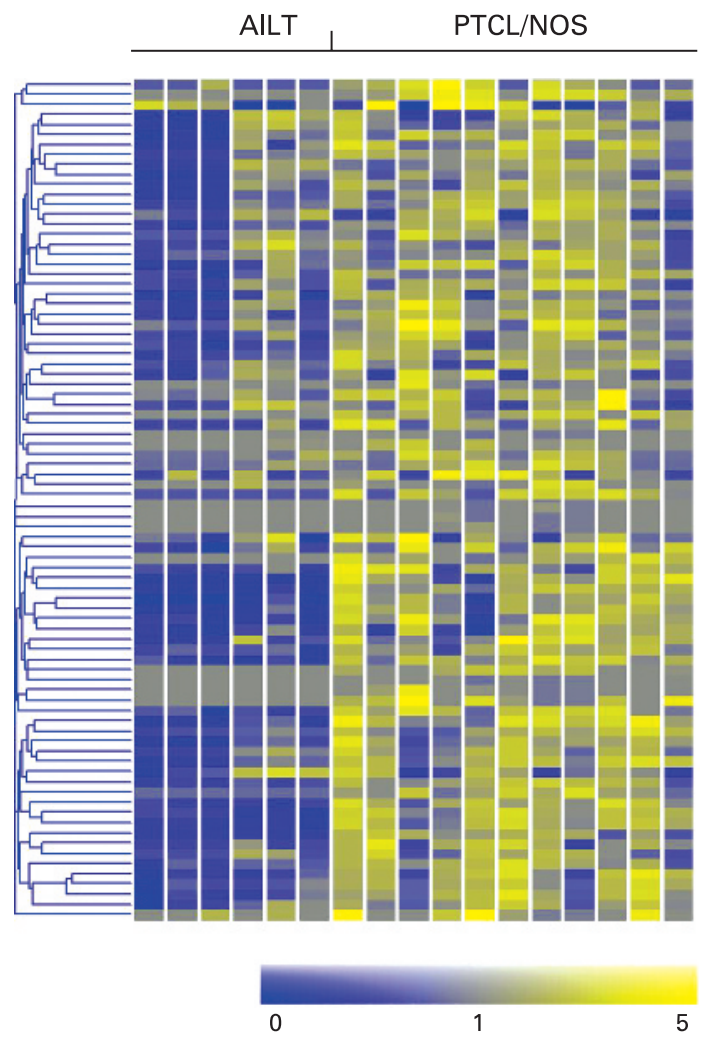

Figure 2 Peripheral T cell lymphoma, not otherwise specified (PTCL/ NOS), and peripheral T cell lymphoma, angioimmunoblastic type (AILT), can be distinguished according to their gene expression profile. Eightythree differentially expressed genes are plotted in the matrix.

confirmed in our PTCL tissue microarray (unpublished observation).

\section{PTCL/NOS versus ALCL}

Lamant et $a l^{16}$ reported that ALK-positive and ALK-negative ALCL have different GEPs. In particular, they found that $B C L-6$, $P T P N 12, C / E B P \beta$ and serpinA1 genes overexpressed in ALKpositive ALCL, a result also confirmed at the protein level. In contrast, the molecular signature of ALK-negative ALCL included overexpression of CCR7, CNTFR, IL22 and IL21 genes, but did not provide any obvious clues to its molecular pathogenesis. This led to the question of whether ALK-negative ALCL should be included in PTCL/NOS. In the course of our GEP study, we found that all ALCL tended to cluster together irrespective of their ALK status, and this signature was clearly distinct from that of PTCL/NOS. ${ }^{20}$ In addition to suggesting that ALK-positive and ALK-negative ALCL probably share a set of deregulated pathways, our findings did not support the proposal that ALK-negative ALCL is a subtype of PTCL/NOS. Such a viewpoint is strengthened by the results of a recent clinicopathological trial showing that ALK-negative ALCLalthough more aggressive than ALK-positive ALCL-has 5-year failure-free and overall survival rates that are significantly better than PTCL/NOS. ${ }^{84}$

\section{Prognosis}

\section{EBV, CD15 and proliferation}

In our series of Italian patients, we found that high Ki-67 expression (see fig 1F), EBV status and CD15 staining were associated with the worst outcome in PTCL/NOS. ${ }^{27}$
Interestingly, a proliferation signature has recently been reported to correlate with an aggressive clinical course, ${ }^{18}$ and EBV has repeatedly been proposed as a negative prognosticator in PTCL.589091 No other phenotypic marker alone or in combination was associated with a poor outcome, although patients with tumours expressing a CD57 or CD4+/CD8profile showed a tendency towards a more favourable outcome, as also observed by others. ${ }^{25} 48$

\section{Clinicopathological score}

Based on our collective results and those published in the literature, ${ }^{26}{ }^{58} 92-96$ we developed a new score that integrates patient- and tumour-specific characteristics (age $\geqslant 60$ years, performance status, lactate dehydrogenase, and Ki-67 marking $>80 \%$ ) and identifies three clear-cut groups of patients with different prognosis. Such a score seems to be more effective than previous indices, including international prognostic index and prognostic index for peripheral $\mathrm{T}$ cell lymphoma, not otherwise specified. $^{26}$

\section{CYP3A}

Recently, Rodríguez-Antona et a ${ }^{97}$ measured tumour CYP3A mRNA content in $44 \mathrm{~T}$ cell lymphomas and found a large variation in its expression that might be due to gains affecting the corresponding gene. To test whether CYP3A could influence PTCL treatment outcome, its expression levels were compared with the patient clinical response and survival, and it was observed that a high CYP3A4 expression was significantly associated with a lower complete remission rate. These results indicate that CYP3A as a potential predictor of tumour chemosensitivity.

\section{NF-kB pathway}

Different GEP studies have suggested that PTCL/NOS may show up- or downregulation of NF- $\mathrm{KB}$ molecules, ${ }^{14} 1598$ with possible prognostic implications (see above). ${ }^{14}{ }^{98}$ However, these studies included a limited number of PTCL/NOS ${ }^{14}$ or cases with prominent non-neoplastic components. ${ }^{15}$ By contrast, we found that PTCL/NOS mostly consisting of neoplastic cells present with global downregulation of NF- $\mathrm{KB}$ genes in comparison with normal $\mathrm{T}$ lymphocytes. This observation was corroborated by consistent cytoplasmic localisation of NF- $\kappa \mathrm{B}$ molecules, the latter moving to the nucleus in the case of NF- $\kappa B$ pathway activation (unpublished observation).

\section{Therapy}

\section{CD4 and CD52 expression}

The in vivo administration of monoclonal antibodies targeted to CD4 and CD52 has recently been proposed for the treatment of patients with PTCL. ${ }^{99}$ However, in our experience this should be regarded with caution when referring to PTCL/NOS. The latter, in fact, characteristically lacks the expression of one or more $T$ cell associated antigens, including those antigens that these antibodies are targeted towards. In particular, we found that CD4 is lacking at the neoplastic cell level in up to $50 \%$ of cases. ${ }^{27}$ CD52 is a molecule expressed by most peripheral blood lymphocytes, macrophages, and monocytes. ${ }^{102}$ Campath- $1 \mathrm{H}$ (alemtuzumab) is a humanised antibody against CD52 currently approved for B cell chronic lymphocytic leukaemia therapy, ${ }^{103-106}$ and it has also shown interesting activity in T prolymphocytic leukaemia and cutaneous TCLs. ${ }^{107}$ Although other factors can affect its response in vivo, the lack of CD52 expression may play a major role in causing refractoriness to 
the compound. Few data are available regarding the use alemtuzumab in PTCL/NOS. ${ }^{108} 109$ We studied the expression of CD52 on tissue microarrays containing $97 \mathrm{PTCL} / \mathrm{NOS}{ }^{21}$ In addition, in 28 cases for which frozen material was available, GEP were generated and compared with those of 20 samples of normal T lymphocytes. ${ }^{21}$ We found that 17/28 (60\%) PTCL/ NOS showed CD52 gene expression level lower than the lowest one recorded in normal $\mathrm{T}$ cells. ${ }^{21}$ In addition, the gene product was detected by immunohistochemistry in 40/97 (41\%) PTCL (see fig 1G). ${ }^{21}$ Interestingly, such data are in keeping with the clinical results obtained by Enblad et a ${ }^{108}$ who found an overall response rate of $36 \%$ in PTCL treated with alemtuzumab. Based on these findings, we think that the estimation of CD52 expression may provide a rationale for the selection of patients with higher probability of responding to alemtuzumab, by avoiding the risk of unwanted toxicity. ${ }^{21}$ Similar conclusions were achieved by Rodig et $a l^{100}$ and Chang et $a l,{ }^{101}$ who reported immunohistochemical detection of CD52 in $0-40 \%$ of PTCL.

\section{PDGFR $\alpha$}

The regular detection of PDGFR $\alpha$ overexpression at the mRNA and protein levels, as well as its frequent phosphorylation (see fig 1D), prompted $u^{20}$ to design an ex vivo experiment aimed testing the sensitivity of PTCL/NOS cells to imatinib, a wellknown PDGFR $\alpha$ inhibitor. ${ }^{110}$ The results obtained were of interest, with about $50 \%$ cytotoxic effect seen at $48 \mathrm{~h}$ with a $1 \mu \mathrm{mol}$ concentration. Such an effect became even higher $(75 \%)$ with a $10 \mu \mathrm{mol}$ dose. Notably, imatinib exerted a limited effect on the viability of normal lymphocytes.

\section{Histone deacetylation}

Since silencing of certain genes (such as GADD45A and $G A D D 45 B)$ can be regulated by epigenetic mechanisms

\section{Take-home messages}

- Peripheral T cell lymphomas (PTCL) represent about $12 \%$ of all lymphoid tumours worldwide. Around half belong to the not otherwise specified (NOS) type.

- Conventional morphological and molecular criteria do not assist in the subclassification of PTCL/NOS, as anthracyclinebased therapies fail to cure it, and most patients die of their disease within 5 years.

- Novel microarray technologies allow the identification of peculiar features that may in turn be useful for the diagnosis, prognosis and treatment of PTCL/NOS.

- PTCL/NOS is characterised by frequent defective expression of $\mathrm{T}$ associated antigens, including CD4 and CD52, which have recently been proposed as targets for humanised monoclonal antibodies.

- The growth fraction $>80 \%$ has a prognostic impact.

- Gene expression profiling studies show derivation from activated peripheral $\mathrm{T}$ lymphocytes and systematic deregulation of 155 genes and related products that may provide the rationale for the unprecedented usage of drugs such as tyrosine kinase and histone deacetylase inhibitors.

- The gene expression profile also contributes to the better definition of the boundaries between PTCL/NOS and angioimmunoblastic $\mathrm{T}$ cell lymphoma, the latter deriving from follicular T helper lymphocytes and characteristically expressing CXCL13 and PD1 along with vascular endothelial growth factor. including acetylation, we tested a histone deacetylase inhibitor (HDACi) (ITF2357) against PTCL/NOS primary cells. Notably, the compound induced dramatic G0-G1 cell cycle arrest and apoptosis at therapeutic concentrations, suggesting a possible role for this class of drugs in PTCL/NOS therapy, as also supported by preliminary clinical observations. ${ }^{111}$ Interestingly, the combination of ITF2357 and daunorubicin apparently had a slight additive effect, as already observed with other HDACi. ${ }^{112}$

\section{VEGF}

Recently, we observed upregulation of the VEGF gene in AITL. ${ }^{22}$ The same finding had previously been reported by de Leval et $a l^{17}$ who had attributed it to the rich vascular component of the tumour. However, by immunohistochemistry on tissue microarrays, we showed that neoplastic cells strongly express both VEGF (see fig $1 \mathrm{H}$ ) and its receptor KDR. ${ }^{22}$ This fact suggests possible AITL sensitivity to anti-angiogenetic drugs, such as thalidomide and bevacizumab. ${ }^{113}$

\section{CONCLUSIONS}

For a long time, PTCL have represented an orphan pathology. This can be explained by their relatively low prevalence (which is in any case higher than that of a "common" tumour, such as $\mathrm{CHL}$ ), diagnostic difficulties and dismal prognosis. Based on recent advances in the genomic and translational fields, a new scenario can now be envisaged leading the way to more successful therapeutic strategies. This may be the right time to live a dream, never forgetting however that "the truth is not always pure and never simple" (Oscar Wilde).

Funding: Associazione Italiana per la Ricerca sul Cancro (AIRC, Milan, Italy), Ministero dell'Università e della Ricerca Scientifica e Tecnologica (PRIN/COFIN and FIRB, Rome, Italy), BolognAlL (Bologna, Italy) and Fondazione Cassa di Risparmio in Bologna (Bologna, Italy).

Competing interests: None.

\section{REFERENCES}

1. Jaffe ES, Harris NL, Stein H, Vardiman JW, eds. Pathology and genetics: tumours of haematopoietic and lymphoid tissues (World Health Organization Classification of Tumours). Lyon: IARC Press, 2001

2. Zucca E, Zinzani PL. Understanding the group of peripheral T-cell lymphomas, unspecified. Curr Hematol Rep 2005;4:23-30.

3. Harris NL, Jaffe ES, Stein $\mathrm{H}$, et al. A revised European-American classification of lymphoid neoplasms: a proposal from the International Lymphoma Study Group. Blood 1994;84:1361-92.

4. Evens AM, Gartenhaus RB. Treatment of T-cell non-Hodgkin's lymphoma. Curr Treat Options Oncol 2004:5:289-303.

5. Lopez-Guillermo A, Cid J, Salar A, et al. Peripheral T-cell lymphomas: initia features, natural history, and prognostic factors in a series of 174 patients diagnosed according to the REAL Classification. Ann Oncol 1998;9:849-55.

6. de Leval L, Savilo E, Longtine J, et al. Peripheral T-cell lymphoma with follicular involvement and a CD4+/bcl-6+ phenotype. Am J Surg Pathol 2001;25:395-400.

7. Rudiger T, Ichinohasama R, Ott MM, et al. Peripheral T-cell lymphoma with distinct perifollicular growth pattern: a distinct subtype of T-cell lymphoma? Am J Surg Pathol 2000:24:117-22.

8. Geissinger E, Odenwald T, Seung-Souk L, et al. Nodal peripheral T-cell lymphomas and, in particular, their lymphoepithelioid (Lennert's) variant are often derived from CD8+ cytotoxic cells. Virchows Arch 2004;445:334-43.

9. Gisselbrecht C, Gaulard P, Lepage E, et al. Prognostic significance of T-cell phenotype in aggressive non-Hodgkin's lymphomas. Groupe d'Etudes des Lymphomes de l'Adulte (GELA). Blood 1998;92:76-82.

10. The Non-Hodgkin's Lymphoma Classification Project. Effect of age on the characteristics and clinical behavior of non-Hodgkin's lymphoma patients. Ann Oncol 1997;8:973-8.

11. Rudiger T, Weisenburger DD, Anderson JR, et al. Peripheral T-cell lymphoma (excluding anaplastic large-cell lymphoma): results from the Non-Hodgkin's Lymphoma Classification Project. Ann Oncol 2002;13:140-9.

12. Zettl A, Rudiger T, Konrad MA, et al. Genomic profiling of peripheral T-cell lymphoma, unspecified, and anaplastic large T-cell lymphoma delineates novel recurrent chromosomal alterations. Am J Pathol 2004;164:1837-48.

13. Oshiro A, Tagawa H, Ohshima K, et al. Identification of subtype-specific genomic alterations in aggressive adult T-cell leukemia/lymphoma. Blood 2006;107:4500-7. 
14. Martinez-Delgado B, Melendez B, Cuadros M, et al. Expression profiling of T-cell lymphomas differentiates peripheral and lymphoblastic lymphomas and defines survival related genes. Clin Cancer Res 2004;10:4971-82.

15. Ballester B, Ramuz 0, Gisselbrecht C, et al. Gene expression profiling identifies molecular subgroups among nodal peripheral T-cell lymphomas. Oncogene 2006:25:1560-70.

16. Lamant L, De Reynies A, Duplantier MM, et al. Gene expression profiling of systemic anaplastic large cell lymphoma reveals differences depending on ALK status and two distinct morphological ALK+ subtypes. Blood 2007;109:2156-64.

17. de Leval L, Rickman DS, Thielen $C$, et al. The gene expression profile of nodal peripheral T-cell lymphoma demonstrates a molecular link between angioimmunoblastic T-cell lymphoma (AITL) and follicular helper T (TFH) cells. Blood 2007; 109:4952-63.

18. Cuadros M, Dave SS, Jaffe ES, et al. Identification of a proliferation signature related to survival in nodal peripheral T-cell lymphomas. J Clin Oncol 2007;25:3321-9.

19. Piccaluga PP, Agostinelli C, Zinzani PL, et al. Expression of platelet-derived growth factor receptor $\alpha$ in peripheral T-cell lymphoma not otherwise specified. Lancet Oncol 2005;6:440

20. Piccaluga PP, Agostinelli C, Califano A, et al. Gene expression analysis of peripheral $T$ cell lymphoma, unspecified, reveals distinct profiles and new potential therapeutic targets. J Clin Invest 2007;117:823-34.

21. Piccaluga PP, Agostinelli C, Righi $\mathrm{S}$, et al. Expression of CD52 in peripheral T-cell lymphoma. Haematologica 2007;92:566-7.

22. Piccaluga PP, Agostinelli C, Califano A, et al. Gene expression analysis of angioimmunoblastic lymphoma indicates derivation from $T$ follicular helper cells and vascular endothelial growth factor deregulation. Cancer Res 2007;67:10703-10.

23. Jantunen $\mathbf{E}$, Wiklund $T$, Juvonen $\mathbf{E}$, et al. Autologous stem cell transplantation in adult patients with peripheral T-cell lymphoma: a nation-wide survey. Bone Marrow Transplant 2004;33:405-10

24. Kahl C, Leithauser M, Wolff D, et al. Treatment of peripheral T-cell lymphomas (PTCL) with high-dose chemotherapy and autologous or allogeneic hematopoietic transplantation. Ann Hematol 2002;81:646-50.

25. Kojima H, Hasegawa Y, Suzukawa K, et al. Clinicopathological features and prognostic factors of Japanese patients with "peripheral T-cell lymphoma, unspecified" diagnosed according to the WHO classification. Leuk Res 2004;28:1287-92.

26. Gallamini A, Stelitano C, Calvi R, et al. Peripheral T-cell lymphoma unspecified (PTCL-U): a new prognostic model from a retrospective multicentric clinical study. Blood 2004;103:2474-9.

27. Went $\mathbf{P}$, Agostinelli C, Gallamini A, et al. Marker expression in peripheral T-cell lymphoma: a proposed clinical-pathologic prognostic score. J Clin Oncol 2006;24:2472-9.

28. Au WY, Ma SY, Chim CS, et al. Clinicopathologic features and treatment outcome of mature T-cell and natural killer-cell lymphomas diagnosed according to the World Health Organization classification scheme: a single center experience of 10 years. Ann Oncol 2005;16:206-14.

29. Ascani S, Zinzani PL, Gherlinzoni F, et al. Peripheral T-cell lymphomas. Clinicopathologic study of 168 cases diagnosed according to the REAL Classification. Ann Oncol 1997;8:583-92.

30. Boulland $\mathbf{M L}$, Kanavaros $\mathrm{P}$, Wechsler $\mathrm{J}$, et al. Cytotoxic protein expression in natural killer cell lymphomas and in $\alpha \beta$ and $\gamma \delta$ peripheral T cell lymphomas. J Pathol 1997; 183:432-9.

31. Chott A, Augustin I, Wrba F, et al. Peripheral T-cell lymphomas: a clinicopathologic study of 75 cases. Hum Pathol 1990;21:1117-25.

32. Doi S, Nasu K, Arita $Y$, et al. Immunohistochemical analysis of peripheral T-cell lymphoma in Japanese patients. Am J Clin Pathol 1989;91:152-8.

33. Feller AC, Griesser $\mathrm{H}$, Schilling CV, et al. Clonal gene rearrangement patterns correlate with immunophenotype and clinical parameters in patients with angioimmunoblastic lymphadenopathy. Am J Pathol 1988;133:549-56.

34. Kaneko Y, Maseki N, Sakurai M, et al. Characteristic karyotypic pattern in T-cell lymphoproliferative disorders with reactive "angioimmunoblastic lymphadenopathy with dysproteinemia-type" features. Blood 1988;72:413-21.

35. Knecht H, Odermatt BF, Maurer R, et al. Diagnostic and prognostic value of monoclonal antibodies in immunophenotyping of angioimmunoblastic lymphadenopathy/lymphogranulomatosis X. Br J Haematol 1987;67:19-24.

36. Nakamura $\mathbf{S}$, Suchi T. A clinicopathologic study of node-based, low-grade, peripheral T-cell lymphoma. Angioimmunoblastic lymphoma, T-zone lymphoma, and lymphoepithelioid lymphoma. Cancer 1991;67:2566-78.

37. Namikawa R, Suchi T, Ueda R, et al. Phenotyping of proliferating lymphocytes in angioimmunoblastic lymphadenopathy and related lesions by the double immunoenzymatic staining technique. Am J Pathol 1987:127:279-87.

38. Ohsaka A, Saito K, Sakai T, et al. Clinicopathologic and therapeutic aspects of angioimmunoblastic lymphadenopathy-related lesions. Cancer 1992;69:1259-67.

39. Ohshima K, Kikuchi M, Hashimoto M, et al. Genetic changes in atypical hyperplasia and lymphoma with angioimmunoblastic lymphadenopathy and dysproteinaemia in the same patients. Virchows Arch 1994:425:25-32.

40. Ree HJ, Kadin ME, Kikuchi M, et al. Angioimmunoblastic lymphoma (AlLD-type T-cell lymphoma) with hyperplastic germinal centers. Am J Surg Pathol 1998;22:643-55.

41. Richel DJ, Lepoutre JM, Kapsenberg JG, et al. Epstein-Barr virus in a CD8-positive T cell lymphoma. Am J Pathol 1990;136:1093-9.

42. Takagi N, Nakamura S, Ueda R, et al. A phenotypic and genotypic study of three node-based, low-grade peripheral T-cell lymphomas: angioimmunoblastic lymphoma, T-zone lymphoma, and lymphoepithelioid lymphoma. Cancer 1992:69:2571-82.

43. Tobinai K, Minato K, Ohtsu T, et al. Clinicopathologic, immunophenotypic, and immunogenotypic analyses of immunoblastic lymphadenopathy-like T-cell lymphoma. Blood 1988;72:1000-6.

44. Weiss LM, Strickler JG, Dorfman DM, et al. Clonal T cell populations in angioimmunoblastic lymphadenopathy and angioimmunoblastic lymphadenopathylike lymphoma. Am J Pathol 1986;122:392-7.

45. Lee SS, Rudiger T, Odenwald T, et al. Angioimmunoblastic T cell lymphoma is derived from mature T-helper cells with varying expression and loss of detectable CD4. Int J Cancer 2003;103:12-20.

46. Barth TF, Leithauser F, Dohner $\mathrm{H}$, et al. Primary gastric apoptosis-rich T-cell lymphoma co-expressing CD4, CD8, and cytotoxic molecules. Virchows Arch 2000; 436:357-64.

47. Yamamoto Y, Kitajima H, Sakihana H, et al. CD3+CD4-CD8-TCR-alphabeta+ T cell lymphoma with clinical features of primary effusion lymphoma: an autopsy case. Int J Hematol 2001:74:442-6.

48. Bekkenk MW, Vermeer MH, Jansen PM, et al. Peripheral T-cell lymphomas unspecified presenting in the skin: analysis of prognostic factors in a group of 82 patients. Blood 2003:102:2213-9.

49. Lanier LL, Le AM, Civin Cl, et al. The relationship of CD16 (Leu-11) and Leu-19 (NKH-1) antigen expression on human peripheral blood NK cells and cytotoxic $\mathrm{T}$ lymphocytes. J Immunol 1986;136:4480-6.

50. Knowles DM. Immunohistochemical markers useful in the diagnosis and classification of hematopoietic neoplasms. In: Knowles DM, ed. Neoplastic hematopathology. 2nd edn. Philadelphia: Lippincott Williams \& Wilkins, 2001:93-226.

51. Blakolmer K, Vesely M, Kummer JA, et al. Immunoreactivity of B-cell markers (CD79a, L26) in rare cases of extranodal cytotoxic peripheral T- (NK/T-)cell lymphomas. Mod Pathol 2000;13:766-72.

52. Quintanilla-Martinez L, Preffer F, Rubin D, et al. CD20+ T-cell lymphoma Neoplastic transformation of a normal T-cell subset. Am J Clin Pathol 1994:102:483-9

53. Yao X, Teruya-Feldstein J, Raffeld M, et al. Peripheral T-cell lymphoma with aberrant expression of CD79a and CD20: a diagnostic pitfall. Mod Pathol 2001:14:105-10.

54. Barry TS, Jaffe ES, Sorbara L, et al. Peripheral T-cell lymphomas expressing CD30 and CD15. Am J Surg Pathol 2003;27:1513-22.

55. Gorczyca W, Tsang P, Liu Z, et al. CD30-positive T-cell lymphomas co-expressing CD15: an immunohistochemical analysis. Int J Oncol 2003;22:319-24.

56. Browne $\mathbf{P}$, Petrosyan $\mathrm{K}$, Hernandez $\mathrm{A}$, et al. The B-cell transcription factors BSAP, Oct-2, and BOB.1 and the pan-B-cell markers CD20, CD22, and CD79a are useful in the differential diagnosis of classic Hodgkin lymphoma. Am J Clin Pathol 2003:120:767-77.

57. Tzankov AS, Went PT, Munst S, et al. Rare expression of BSAP (PAX-5) in mature T-cell lymphomas. Mod Pathol 2007;20:632-7.

58. Dupuis J, Emile JF, Mounier N, et al. Prognostic significance of Epstein-Barr virus in nodal peripheral T-cell lymphoma, unspecified: A Groupe d'Etude des Lymphomes de l'Adulte (GELA) study. Blood 2006:108:4163-9.

59. Mahadevan D, Spier C, Della Croce K, et al. Transcript profiling in peripheral T-cel lymphoma, not otherwise specified, and diffuse large B-cell lymphoma identifies distinct tumor profile signatures. Mol Cancer Ther 2005:4:1867-79.

60. Tracey L, Villuendas R, Dotor AM, et al. Mycosis fungoides shows concurrent deregulation of multiple genes involved in the TNF signaling pathway: an expression profile study. Blood 2003;102:1042-50.

61. Tapper J, Kettunen E, El-Rifai W, et al. Changes in gene expression during progression of ovarian carcinoma. Cancer Genet Cytogenet 2001;128:1-6.

62. Sado Y, Kagawa M, Naito I, et al. Organization and expression of basement membrane collagen IV genes and their roles in human disorders. J Biochem (Tokyo) 1998; 123:767-76.

63. van den Boom J, Wolter $M$, Kuick $R$, et al. Characterization of gene expression profiles associated with glioma progression using oligonucleotide-based microarray analysis and real-time reverse transcription-polymerase chain reaction. Am J Pathol 2003;163:1033-43.

64. Jin S, Tong T, Fan W, et al. GADD45-induced cell cycle G2-M arrest associates with altered subcellular distribution of cyclin B1 and is independent of p38 kinase activity. Oncogene 2002:21:8696-704

65. Papa S, Zazzeroni F, Bubici C, et al. Gadd45 beta mediates the NF- $\kappa$ B suppression of JNK signalling by targeting MKK7/JNKK2. Nat Cell Biol 2004:6:146-53.

66. Chen F, Lu Y, Zhang Z, et al. Opposite effect of NF- $\mathrm{BB}$ and c-Jun N-terminal kinase on p53-independent GADD45 induction by arsenite. J Biol Chem 2001;276:11414-9.

67. Hirose T, Sowa Y, Takahashi S, et al. p53-independent induction of Gadd45 by histone deacetylase inhibitor: coordinate regulation by transcription factors 0ct-1 and NF-Y. Oncogene 2003;22:7762-73.

68. Tan K0, Tan KM, Chan SL, et al. MAP-1, a novel proapoptotic protein containing a $\mathrm{BH} 3$-like motif that associates with Bax through its Bcl-2 homology domains. J Biol Chem 2001;276:2802-7.

69. Nagashima M, Shiseki M, Pedeux RM, et al. A novel PHD-finger motif protein, p47ING3, modulates p53-mediated transcription, cell cycle control, and apoptosis Oncogene 2003:22:343-50.

70. Gunduz M, Ouchida M, Fukushima K, et al. Allelic loss and reduced expression of the ING3, a candidate tumor suppressor gene at $7 \mathrm{q} 31$, in human head and neck cancers. Oncogene 2002:21:4462-70. 
71. Lee MS, Hanspers K, Barker CS, et al. Gene expression profiles during human CD4+ T cell differentiation. Int Immunol 2004;16:1109-24.

72. Chtanova T, Newton R, Liu SM, et al. Identification of T cell-restricted genes, and signatures for different $\mathrm{T}$ cell responses, using a comprehensive collection of microarray datasets. J Immunol 2005;175:7837-47.

73. Chtanova T, Tangye SG, Newton R, et al. T follicular helper cells express a distinctive transcriptional profile, reflecting their role as non-Th1/Th2 effector cells that provide help for B cells. J Immunol 2004;173:68-78.

74. Hosack DA, Dennis G Jr, Sherman BT, et al. Identifying biological themes within lists of genes with EASE. Genome Biol 2003;4:R70.

75. Han JS, Macarak E, Rosenbloom J, et al. Regulation of Cyr61/CCN1 gene expression through RhoA GTPase and p38MAPK signaling pathways. Eur $J$ Biochem 2003;270:3408-21.

76. Leu SJ, Liu Y, Chen N, et al. Identification of a novel integrin alpha 6 beta 1 binding site in the angiogenic inducer CCN1 (CYR61). J Biol Chem 2003;278:33801-8.

77. Schober JM, Lau LF, Ugarova TP, et al. Identification of a novel integrin alphaMbeta2 binding site in CCN1 (CYR61), a matricellular protein expressed in healing wounds and atherosclerotic lesions. J Biol Chem 2003;278:25808-15.

78. Tsai MS, Bogart DF, Castaneda JM, et al. Cyr61 promotes breast tumorigenesis and cancer progression. Oncogene 2002;21:8178-85.

79. Tsai MS, Hornby AE, Lakins J, et al. Expression and function of CYR61, an angiogenic factor, in breast cancer cell lines and tumor biopsies. Cancer Res 2000;60:5603-7.

80. Lin MT, Chang CC, Chen ST, et al. Cyr61 expression confers resistance to apoptosis in breast cancer MCF-7 cells by a mechanism of NF-kappaB-dependent XIAP upregulation. J Biol Chem 2004;279:24015-23.

81. Kassem H, Sangar V, Cowan R, et al. A potential role of heat shock proteins and nicotinamide $\mathrm{N}$-methyl transferase in predicting response to radiation in bladder cancer. Int J Cancer 2002;101:454-60.

82. $\mathbf{X u} \mathbf{J}$, Capezzone $\mathrm{M}, \mathrm{Xu} \mathbf{X}$, et al. Activation of nicotinamide $\mathrm{N}$-methyltransferase gene promoter by hepatocyte nuclear factor-1 1 beta in human papillary thyroid cancer cells. Mol Endocrinol 2005;19:527-39.

83. Rudiger T, Geissinger E, Muller-Hermelink HK. "Normal counterparts" of nodal peripheral T-cell lymphoma. Hematol Oncol 2006;24:175-80

84. Savage KJ, Harris NL, Vose MJ, et al. ALK-negative anaplastic large-cell lymphoma (ALCL) is clinically and immunophenotypically different from both ALK+ ALCL and peripheral T-cell lymphoma, not otherwise specified: Report from International Peripheral T-cell Lymphoma Project. Blood 2008;111:5496-504.

85. Attygalle A, Al-Jehani R, Diss TC, et al. Neoplastic T cells in angioimmunoblastic Tcell lymphoma express CD10. Blood 2002;99:627-33.

86. Attygalle $\mathbf{A D}$, Diss TC, Munson P, et al. CD10 expression in extranodal dissemination of angioimmunoblastic T-cell lymphoma. Am J Surg Pathol 2004; 28:54-61.

87. Dupuis J, Boye K, Martin N, et al. Expression of CXCL13 by neoplastic cells in angioimmunoblastic T-cell lymphoma (AITL): a new diagnostic marker providing evidence that AITL derives from follicular helper T cells. Am J Surg Pathol 2006; 30:490-4.

88. Grogg KL, Attygale AD, Macon WR, et al. Expression of CXCL13, a chemokine highly upregulated in germinal center T-helper cells, distinguishes angioimmunoblastic T-cell lymphoma from peripheral T-cell lymphoma, unspecified. Mod Pathol 2006;19:1101-7.

89. Roncador G, Garcia Verdes-Montenegro JF, Tedoldi S, et al. Expression of two markers of germinal center T cells (SAP and PD-1) in angioimmunoblastic T-cell lymphoma. Haematologica 2007;92:1059-66.

90. Cheng AL, Su IJ, Chen YC, et al. Characteristic clinicopathologic features of Epstein-Barr virus-associated peripheral T-cell lymphoma. Cancer 1993;72:909-16.

91. Kluin PM, Feller A, Gaulard P, et al. Peripheral T/NK-cell lymphoma: a report of the IXth Workshop of the European Association for Haematopathology. Histopathology 2001;38:250-70.
92. Caulet-Maugendre S, Patey M, Granier E, et al. Quantitative analysis of cellular proliferative activity in $35 \mathrm{~T}$-cell non-Hodgkin's lymphomas. Use of proliferating cell nuclear antigen and Ki-67 (MIB-1) antibodies and nucleolar organizer regions. Anal Quant Cytol Histol 1996;18:337-44.

93. Miller TP, Grogan TM, Dahlberg S, et al. Prognostic significance of the Ki-67associated proliferative antigen in aggressive non-Hodgkin's lymphomas: a prospective Southwest Oncology Group trial. Blood 1994;83:1460-6.

94. Mochen C, Giardini R, Costa A, et al. MIB-1 and S-phase cell fraction predict survival in non-Hodgkin's lymphomas. Cell Prolif 1997;30:37-47.

95. Montalban C, Obeso G, Gallego A, et al. Peripheral T-cell lymphoma: a clinicopathological study of 41 cases and evaluation of the prognostic significance of the updated Kiel classification. Histopathology 1993;22:303-10.

96. Sheval EV, Churakova JV, Dudnik OA, et al. Examination of the proliferative activity of tumor cells in human lymphoid neoplasms using a morphometric approach. Cancer 2004:102:174-85.

97. Rodríguez-Antona C, Leskela S, Zajac M, et al. Expression of CYP3A4 as a predictor of response to chemotherapy in peripheral T-cell lymphomas. Blood 2007:110:3345-51.

98. Martinez-Delgado B, Cuadros M, Honrado E, et al. Differential expression of NFkappaB pathway genes among peripheral T-cell lymphomas. Leukemia 2005:19:2254-63.

99. Rider DA, Havenith CE, de Ridder R, et al. A human CD4 monoclonal antibody for the treatment of T-cell lymphoma combines inhibition of T-cell signaling by a dual mechanism with potent Fc-dependent effector activity. Cancer Res 2007;67:9945-53.

100. Rodig SJ, Abramson JS, Pinkus GS, et al. Heterogeneous CD52 expression among hematologic neoplasms: implications for the use of alemtuzumab (CAMPATH-1H). Clin Cancer Res 2006;12:7174-9.

101. Chang ST, Lu CL, Chuang SS. CD52 expression in non-mycotic T- and NK/T-cell Iymphomas. Leuk Lymphoma 2007:48:117-21.

102. Gilleece MH, Dexter TM. Effect of Campath-1H antibody on human hematopoietic progenitors in vitro. Blood 1993;82:807-12

103. Hale G, Dyer MJ, Clark MR, et al. Remission induction in non-Hodgkin lymphoma with reshaped human monoclonal antibody CAMPATH-1H. Lancet 1988;2:1394-9.

104. Hale G, Waldmann H. CAMPATH-1 monoclonal antibodies in bone marrow transplantation. J Hematother 1994;3:15-31.

105. Keating MJ, Flinn I, Jain V, et al. Therapeutic role of alemtuzumab (Campath-1H) in patients who have failed fludarabine: results of a large international study. Blood 2002;99:3554-61

106. Rai KR, Freter CE, Mercier RJ, et al. Alemtuzumab in previously treated chronic lymphocytic leukemia patients who also had received fludarabine. J Clin Oncol 2002;20:3891-7.

107. Dearden C. The role of alemtuzumab in the management of T-cell malignancies. Semin Oncol 2006;33(2 Suppl 5):S44-52.

108. Enblad G, Hagberg H, Erlanson M, et al. A pilot study of alemtuzumab (anti-CD52 monoclonal antibody) therapy for patients with relapsed or chemotherapy-refractory peripheral T-cell lymphomas. Blood 2004;103:2920-4.

109. Gallamini A, Zaja F, Patti C, et al. Alemtuzumab (Campath-1H) and CHOP chemotherapy as first-line treatment of peripheral T-cell lymphoma: results of a GITIL (Gruppo Italiano Terapie Innovative nei Linfomi) prospective multicenter trial. Blood 2007:110:2316-23.

110. Peng B, Hayes M, Resta D, et al. Pharmacokinetics and pharmacodynamics of imatinib in a phase I trial with chronic myeloid leukemia patients. J Clin Oncol 2004;22:935-42

111. Duvic M, Vu J. Vorinostat: a new oral histone deacetylase inhibitor approved for cutaneous T-cell lymphoma. Expert Opin Investig Drugs 2007;16:1111-20.

112. Sanchez-Gonzalez B, Yang H, Bueso-Ramos C, et al. Antileukemia activity of the combination of an anthracycline with a histone deacetylase inhibitor. Blood 2006;108:1174-82.

113. Aguiar Bujanda D. Complete response of relapsed angioimmunoblastic T-cell lymphoma following therapy with bevacizumab. Ann Oncol 2008;19:396-7. 